\title{
Da soberania aos micropoderes: aporias no ensino jurídico concebido no poder soberano
}

\section{From sovereignty to micropowers: aporias within Law education conceived in the sovereign power}

José Ourismar Barros ${ }^{1}$

\section{Resumo}

Trata-se de trabalho apresentado no "GT 5 - O projeto pedagógico e a realidade brasileira: a função dos cursos jurídicos em um país em desenvolvimento" do "Seminário Ensino Jurídico e Formação Docente", em que se visa apontar, por meio do método arqueológico de pesquisa, aporias nos projetos pedagógicos e grades curriculares das faculdades de Direito hoje no Brasil, geralmente fundamentados numa visão político-filosófico da soberania estatal mostrando-se inadequado diante da complexidade da realidade atual caracterizada pela existência de múltiplas fontes de decisão normativa e de poder.

Palavras-chave: Soberania. Micropoderes. Ensino. Jurídico. Inadequação.

\begin{abstract}
This study is to be presented at the "GT 5 - Pedagogical Project and the Brazilian Reality: the objective of Law courses in a developing country" of the "Seminar on Law Education and Teacher Training and Educational Background". It aims at pointing out aporias within the pedagogical projects and curriculums of Law colleges in Brazil, which are usually grounded on a politically-philosophically State sovereignty, which is inadequate before the complexity of current reality, characterized by the existence of multiple sources of decision regarding laws and power.
\end{abstract}

Key-words: Sovereignty. Micropowers. Legal Education. Inadequacy

1 Professor substituto da Universidade Federal de Viçosa e Professor da Universidade Santo Agostinho de Sete Lagoas. Especialista em Direito Público e mestrando em Direito pela Universidade Federal de Minas Gerais. Link currículo Lattes do autor: http://buscatextual.cnpq.br/buscatextual/visualizacv. do?id=K4467454T6 


\section{Introdução}

\subsection{Problematização}

O ensino jurídico hoje no Brasil, início do século XXI, é ainda estruturado com base nos fundamentos de um Estado concebido a partir do pensamento do contrato social, do consenso social, de verdades a serem atingidas e do direito natural, com origem nos séculos XVI, XVII e XVIII. Tal concepção de Estado é incompatível com os problemas e situações de alta complexidade social que caracterizam a nossa sociedade atual.

Assim, o problema a ser enfrentado neste trabalho é a existência de programas institucionais, grades curriculares e o próprio ensino jurídico constituídos, construídos e mantidos na concepção do Estado moderno que se caracteriza pela manifestação do poder soberano, o que se manifesta inadequado diante da atual complexidade das relações humanas e dos conflitos humanos com múltiplas fontes de poder.

\subsection{Metodologia}

A pesquisa presente neste trabalho alinha-se à vertente jurídico-sociológica, inter-relacionando a dogmática jurídica aos fenômenos sociais, dando a ciência jurídica bases de intervenções adequadas no seio social. É nesse sentido que vemos o Direito numa intensa interação dialética com a realidade social, dela não podendo estar desassociada. As pesquisas jurídicas devem ser alimentadas pela realidade e a realidade ser alimentada pelos resultados das pesquisas. ${ }^{2}$

Noutro passo, nossa investigação dar-se-á por meio do raciocínio arqueológico, consistente em saber como "a representação, o discurso e o conhecimento estão envolvidos com práticas sociais e o poder"3, assim descobrir, no poder régio ou na soberania, o embrião da prática do ensino jurídico no Brasil nos dias de hoje.

\subsection{Justificativa}

A importância de enfrentamento do tema é latente: a estrutura do ensino jurídico presa a concepções

2 GUSTIN, Miracy B. S.; DIAS, Maria Tereza Fonseca. (Re)pensando a pesquisa jurídica: teoria e prática. 2. ed. Belo Horizonte: Del Rey, 2006. p. 20.

3 GONÇALVES, Sérgio Campos. O método arqueológico de análise discursiva: o percurso metodológico de Michel Foulcault. História e-História, Campinas: NEE-UNICAMP, v. 1, p. 1-21, 4 fev. 2009. de que todo poder tem fonte no soberano impede os estudantes de Direito de compreender o caráter conflitivista da sociedade atual, deixando-os alheios aos reais problemas da pós-modernidade, tais como: interesses de grupos antagônicos, múltiplas fontes de decisão, erosão do conceito de soberania, diluição das fronteiras físicas, esvaziamento do protagonismo político do Estado-nação etc. Bem resume a complexa realidade atual a seguinte passagem de José Eduardo Faria:

À medida que o tradicional modelo de 'direito positivo' entra em crise de identidade, funcionalidade e eficácia, acarretando com isso uma crescente erosão do rigor analítico e do potencial explicativo dos esquemas teóricos desenvolvidos com base no primado do monismo jurídico, outro modelo vai surgindo. [...] Por exemplo, ele se destaca por feições pluralistas, sob forma de redes de legalidade justapostas ou paralelas, resultantes não apenas de decisões emanadas de instituições governamentais, como Legislativo e o Executivo, mas igualmente, de negociações e deliberações nos diferentes sistemas e subsistemas que compõem a economia e a sociedade. Trata-se de um direito cuja produção normativa cada mais se dá em instancias não-legislativas, motivo pelo qual seu conteúdo normativo não é determinado apenas e tão-somente pelo Estado, porém pactuado por diferentes atores - empresas, fundações, associações comunitárias, entidades de classe, órgãos de representação corporativa e organizações não-governamentais (ONG's). ${ }^{4}$

Em suma, a sociedade atual é caracterizada pela existência de diversas fontes de produção normativa, o que significando a quebra - ainda que de forma não manifestada - do monopólio estatal como fonte do Direito. Significa, também, a existência de múltiplos atores detentores de poder (poder econômico, poder político ou poder punitivo) que se inter-relacionam em manifestações de dominação e dominado sem que haja atuação do Estado para a contenção de arbítrios.

Enfim, o modelo jurídico da soberania não é adequado para uma análise concreta da multiplicidade das relações de poder existentes hoje. ${ }^{5}$

\subsection{Hipótese}

Diante desse contexto, nossa afirmação - mais que simples a reestruturação das grades curriculares - é a as-

4 FARIA, José Eduardo. Sociologia jurídica: direito e conjuntura. 2. ed. São Paulo: Saraiva, 2010.

5 FOUCAULT, Michel. Em defesa da sociedade. Trad.: Maria Ermantina Galvão. São Paulo: Martins Fontes, 2008. p. 49. 
sunção da existência desse cenário conflitivista pelos projetos pedagógicos das nossas faculdades de Direito para se alcançar a adequação entre o que é ensinado em sala de aula e o que realmente ocorre fora dela.

\subsection{Objetivos}

Com isso pretendemos alcançar a significação e origem do Estado moderno, sua conformação histórica, filosófica, política e social - obviamente de maneira meramente enunciativa, sem a que possamos aprofundar nessas questões - que ainda influenciam e determinam a concepção dos projetos pedagógicos das faculdades de Direito hoje no Brasil.

Fixados esses conceitos, passa-se ao inventário de situações que determinam a passagem do poder soberano aos micropoderes para que, ao final, possamos identificar a estrutura do ensino jurídico ligada ao modelo de soberania em contraposição aos fatos atuais originados de múltiplas fontes de poder.

\section{Desenvolvimento}

O Estado, tal como o concebemos hoje, tem suas raízes na filosofia contratualista desenvolvida a partir do século XVI, cujos maiores expoente são Hobbes, Locke e Rousseau com as seguintes obras, respectivamente, Leviatã (1651), Segundo Tratado do Governo Civil (1688) e Contrato Social (1762).

Hobbes utiliza sua teoria contratualista para justificar a monarquia absoluta. ${ }^{6}$ Este pensador entende que o poder do monarca - do soberano - surge da soma dos poderes individuais dos homens:

O maior dos poderes humanos é aquele que é composto pelos poderes de vários homens, unidos por consentimento numa só pessoa, natural ou civil, que tem o uso de todos os seus poderes na dependência de sua vontade: é o caso do poder de um Estado.?

Assim como as demais teorias do contrato social e isso é a característica fundamental das teorias contratualistas -, Hobbes parte do pressuposto que a condição

\footnotetext{
6 FERREIRA FILHO, Manoel Gonçalves. O poder constituinte. São Paulo: Saraiva, 1999. p. 7.

7 HOBBES, Thomas. Leviatã ou matéria, Forma e poder de um estado eclesiástico e civil. Tradução de João Paulo Monteiro e Maria Beatriz Nizza da Silva. 2. ed. São Paulo: Martins Fontes, 2008. p. 76.
}

natural do ser humano é a igualdade, de modo que a existência de pequenas diferenças entre os homens (ou diferenças insignificantes) não podem legitimar tratamentos diferenciados - privilégios - para nenhum dos homens:

A natureza fez os homens tão iguais, quanto às faculdades do corpo e do espírito que, embora por vezes se encontre um homem manifestamente mais forte de corpo, ou de espírito mais vivo do que outro, mesmo assim, quando se considera tudo isto em conjunto, a diferença entre um e outro homem não é suficientemente considerável para que qualquer um possa com base nela reclamar qualquer benefício a que outro não possa também aspirar, tal como ele. Porque quanto à força corporal o mais fraco tem força suficiente para matar o mais forte, quer por secreta maquinação, quer aliando-se com outros que se encontrem ameaçados pelo mesmo perigo. ${ }^{8}$

A condição natural de guerra entre os homens surge em razão dessas condições de igualdade. Uma vez desta condição de igualdade (material e espiritual) surge a esperança dos homens em atingir os seus objetivos; e se dois homens desejam os mesmos objetivos que são impossíveis de serem gozadas ao mesmo tempo, os homens tornam-se inimigos. Ou seja, os homens vivem em constante desconfiança para com os demais. É um imperativo para a sua própria sobrevivência. ${ }^{9}$

Essa desconfiança natural do homem para a sua própria conservação exige a antecipação; isto é, a força ou a astúcia para subjugar os demais durante o tempo necessário para chegar ao momento em que não veja qualquer outro poder suficientemente grande para ameaçá-lo. ${ }^{10}$ Enfim, essa é a condição natural do homem: a condição da guerra, a condição do homem como lobo do próprio homem.

Para que o homem não seja o seu próprio lobo é necessário um poder comum, um poder que surge da soma dos poderes individuais: o Leviatã. Somente com a existência desse poder comum o homem deixa seu estado

8 HOBBES, Thomas. Leviatã ou matéria, forma e poder de um estado eclesiástico e civil. Tradução de João Paulo Monteiro e Maria Beatriz Nizza da Silva. 2. ed. São Paulo: Martins Fontes, 2008.p. 106.

9 HOBBES, Thomas. Leviatã ou matéria, forma e poder de um estado eclesiástico e civil. Tradução de João Paulo Monteiro e Maria Beatriz Nizza da Silva. 2. ed. São Paulo: Martins Fontes, 2008. p. 107.

${ }^{10}$ HOBBES, Thomas. Leviatã ou matéria, forma e poder de um estado eclesiástico e civil. Tradução de João Paulo Monteiro e Maria Beatriz Nizza da Silva. 2. ed. São Paulo: Martins Fontes, 2008.p. 108. 
de guerra natural para ingressar num estado de paz garantido pelo soberano.

A condição de guerra para Hobbes não é somente o momento da batalha ou o ato de lutar, mas a condição para tal, ou seja, a condição ou a predisposição do homem para a batalha, para a luta. Porém, Hobbes crê que, com a criação do Leviatã (poder soberano), as disposições para a guerra são dissipadas, pois as desconfianças entre os homens também são dissipadas, já que há um guardião comum dos objetivos de todos.

A crença de Hobbes na existência da situação de paz duradoura pode ser retirada da seguinte conclusão do autor:

Com isto se torna manifesto que, durante o tempo em que os homens vivem sem um poder comum capaz de os manter a todos em respeito, eles se encontram naquela condição a que se chama guerra; e uma guerra que é de todos os homens contra todos os homens. ${ }^{11}$

Pois, se sem um poder comum os homens estão em condição de guerra, com um poder comum os homens não vivem nessa condição.

Ao contrário da doutrina de Hobbes, as lições contratualista de Rousseau é uma fonte de interpretação para a democracia, "a cláusula fundamental do contrato social consistiria em todos os homens colocarem todos os seus direitos a dispor da vontade geral"12.

Encontramos, então, dois fundamentos nucleares das teorias contratualistas fundamentais para o poder soberano: a igualdade entre os homens e o pacto tácito de cessão de parcela de sua liberdade para a garantia do restante dela.

Essa cessão de parcela da liberdade, para Manoel Gonçalves Ferreira Filho, consiste, em verdade, numa estipulação em favor de terceiro, em que se atribui a um só (o monarca, o governo, o soberano) a função de manter a paz: “[...] o monarca não é parte no contrato; ele é beneficiário de uma estipulação, que poderíamos reduzir ao modelo civilista da estipulação em favor de terceiro." ${ }^{3}$

${ }^{11}$ HOBBES, Thomas. Leviatã ou matéria, forma e poder de um estado eclesiástico e civil. Tradução de João Paulo Monteiro e Maria Beatriz Nizza da Silva. 2. ed. São Paulo: Martins Fontes, 2008. p. 109.

${ }^{12}$ FERREIRA FILHO, Manoel Gonçalves. O poder constituinte. São Paulo: Saraiva, 1999. p. 8.
Segundo este mesmo constitucionalista paulista, as teorias contratuais de Hobbes, Locke e Rousseau são passos que antecedem o surgimento da doutrina do Poder Constituinte. ${ }^{14}$

Chamamos a atenção para a concepção do poder segundo Rousseau, qual inspirou a Declaração dos Direitos do Homem e do Cidadão (DDHC) de 1789: a peculiaridade da divisão dos poderes (ou princípio da divisão dos poderes) que, segundo a DDHC: "não tem Constituição o Estado onde a garantia dos direitos não houver sido estabelecida, nem instaurada a separação dos poderes” (art. 16).

Veja-se que a inspiração da época parece indicar que a única fonte de poder é o poder político, o poder do soberano; sendo que, para que não haja abuso do poder ele deve ser repartido em três e que sirvam reciprocamente de freios e contrapesos; não são três poderes, mas um único poder dividido.

Essa noção de poder da filosofia política dos séculos XVI, XVII e XVIII, é uma noção de poder como propriedade, algo único, e bem retratado por Foucault:

[...] no caso da teoria jurídica clássica de poder, o poder é considerado um direito do qual se seria possuidor como de um bem, e que se poderia, em consequência, transferir ou alienar, de uma forma total ou parcial, mediante um ato jurídico ou um ato fundador de direito [...]. O poder é aquele, concreto, que todo indivíduo detém e que viria a ceder, total ou parcialmente, para construir um poder, uma soberania. ${ }^{15}$

Segundo Michel Foucault, a teoria da soberania desempenhou quatro papeis essenciais: (a) referiu-se ao mecanismo de poder efetivo da monarquia feudal; (b) serviu de instrumento e de justificação para a constituição de grandes monarquias administrativas; (c) foi um instrumento de luta política e teórica em torno dos sistemas de poder dos séculos XVI e XVII; (d) serviu de base para construir, contra as monarquias administrativas, autoritárias ou absolutas, um modelo alternativo: o das democracias parlamentares. ${ }^{16}$

Porém, ainda no século XVIII surge uma nova manifestação de poder: o poder disciplinar. Essa espécie

\footnotetext{
${ }^{14}$ FERREIRA FILHO, Manoel Gonçalves. O poder constituinte. São Paulo: Saraiva, 1999. p.7.

${ }^{15}$ FOUCAULT, Michel. Em defesa da sociedade. Trad.: Maria Ermantina Galvão. São Paulo: Martins Fontes, 2008. p. 20-21.

${ }^{16}$ FOUCAULT, Michel. Em defesa da sociedade. Trad.: Maria Ermantina Galvão. São Paulo: Martins Fontes, 2008. p. 42.
} 
de manifestação de poder - melhor: espécie de manifestação de dominação - que foi desenvolvida por Foucault na obra Vigiar e Punir: história da violência nas prisões.

Esse poder visa a docilização dos corpos; é "um mecanismo que permite extrair dos corpos tempo e trabalho, mais do que bens e riqueza". ${ }^{17}$ "A disciplina aumenta as forças do corpo (em termos econômicos de utilidade) e diminui essas mesmas forças (em termos políticos de obediência)".18

O poder disciplinar, na obra de Foucault, tem como técnica: a distribuição dos indivíduos no espaço - veja, por exemplo, a disposição dos alunos em sala de aula: ${ }^{19} \mathrm{o}$ controle da atividade humana por meio de regulamentação dos ciclos de repetição, elaboração temporal do ato, utilização exaustiva do corpo etc. ${ }^{20}$; a vigilância hierárquica ${ }^{21}$; a sanção normalizadora, consistente na punição imediata com a finalidade de colocar o indivíduo no padrão normal, o que faz do poder disciplinar, segundo Foucault, uma infrapenalidade, algo muito parecido com as leis penais, com suas leis próprias, delitos especificados e suas próprias cortes de julgamento - veja-se, por exemplo, as punições escolares em razão de conversar durante a aula ou não obedecer a regra da fila. ${ }^{22}$

Para Foucault as manifestações de dominação (manifestações de poder) ganhou uma nova forma ainda durante o século XVIII e persistente até os dias atuais: o biopoder.

Vejamos, ao contrário do que ocorre no poder soberano, o poder disciplinar não se materializa na pessoa do rei, mas nos corpos dos sujeitos individualizados por suas técnicas disciplinares. Enquanto que o poder da soberania, ou poder soberano, se apropria e expia os bens e riquezas dos súditos, o poder disciplinar não se detém como uma coisa, não se transfere como uma propriedade.

${ }^{17}$ FOUCAULT, Michel. Em defesa da sociedade. Trad.: Maria Ermantina Galvão. São Paulo: Martins Fontes, 2008.p. 42.

${ }^{18}$ FERREIRA FILHO, Manoel Gonçalves. O poder constituinte. São Paulo: Saraiva, 1999. p. 119.

${ }^{19}$ FOUCAULT, Michel. Em defesa da sociedade. Trad.: Maria Ermantina Galvão. São Paulo: Martins Fontes, 2008. p. 121.

${ }^{20}$ FOUCAULT, Michel. Em defesa da sociedade. Trad.: Maria Ermantina Galvão. São Paulo: Martins Fontes, 2008. p. 127.

${ }^{21}$ FOUCAULT, Michel. Em defesa da sociedade. Trad.: Maria Ermantina Galvão. São Paulo: Martins Fontes, 2008. p. 143.

${ }^{22}$ FOUCAULT, Michel. Em defesa da sociedade. Trad.: Maria Ermantina Galvão. São Paulo: Martins Fontes, 2008. p. 148-149.
Já no biopoder a instrumentalidade do poder não exerce sobre a morte, mas sim sobre a vida; a morte é exatamente o termo final do exercício do poder. O biopoder é exercido sobre a vida no sentido de organiza-la, conhecê-la e controlá-la.

O biopoder tem como técnicas e horizonte de sua projeção: o cálculo, as estatísticas, os dispositivos de segurança, a coletividade (não mais o corpo individualizado mas sim grupos de pessoas), o controle de circulação de mercadorias etc. Em suma, é um poder de recai sobre o corpo; uma "territorialização" do corpo ou "corporização" do território. ${ }^{23}$

Voltando.

Há a necessidade de pensarmos no réquiem da concepção da teoria política e jurídica fundada na soberania de Hobbes. Como vimos, este autor afirma que a existência de um poder comum seria capaz de gerar a paz entre os homens naturalmente inclinados à guerra. Foucault, porém, diz que o exercício da soberania - soberania política propriamente dita - é uma continuação da guerra, sendo "a política é a continuação da guerra por outros meios". ${ }^{24}$ Enfim,

[...] é preciso desvencilhar-se do modelo do Leviatã, desse modelo de um homem artificial, a um só tempo autômato, fabricado e unitário igualmente, que envolveria todos os indivíduos reais e cujo corpo seriam os cidadãos, mas cuja alma seria a soberania. É preciso estudar o poder fora do Leviatã, fora do campo delimitado pela soberania jurídica e pela instituição do Estado; trata-se de analisá-lo a partir das técnicas e táticas de dominação. ${ }^{25}$

Quando Foucault afirma a necessidade de nos desvencilharmos do modelo do Leviatã, fala isso com relação às pesquisas científicas e o modo de pensar como um todo, o que inclui o ensino jurídico; contudo, a prática em sala de aula ainda mantém-se nas explicações dos institutos jurídicos baseados nos modelos clássicos de concepção do Direito.

${ }^{23} \mathrm{O}$ que na soberania o território físico era os limites do exercício de poder, no bipoder o corpo passa a ser o objeto para o exercício de poder. O biopoder é mais bem desenvolvido no curso proferido por Michel Foucault "Segurança, Território e População".

${ }^{24}$ FOUCAULT, Michel. Em defesa da sociedade. Trad.: Maria Ermantina Galvão. São Paulo: Martins Fontes, 2008.p. 32.

${ }^{25}$ FOUCAULT, Michel. Em defesa da sociedade. Trad.: Maria Ermantina Galvão. São Paulo: Martins Fontes, 2008. p. 40. 
O raciocínio simplista da conformação da sociedade por meio de um contrato social é extremamente sedutor para o ensino dos institutos jurídicos, porém, quando esses institutos são confrontados com a complexidade da realidade social o resultado é a sensação de incompreensão por parte do aluno; por exemplo, Cesare de Beccaria afirma que a origem do direito de punir pertencente ao Estado é a soma dos sacrifícios das liberdades individuais:

Cansados de só viver no meio de temores e de encontrar inimigos por toda parte, fatigados de uma liberdade que a incerteza de conservá-la tornava inútil, sacrificaram uma parte dela para gozar do resto com mais segurança. A soma de todas essas porções de liberdade, sacrificadas assim ao bem geral, formou a soberania da nação; e aquele que foi encarregado pelas leis do depósito das liberdades e dos cuidados da administração foi proclamado o soberano do povo. ${ }^{26}$

Parece ser evidente que, diante de uma pergunta de aluno sobre a legitimidade do direito de punir do Estado, essa explicação simplista, da concordância entre os indivíduos em nome do bem comum, mostra-se uma carta na manga para uma resposta convincente.

O mesmo pode ser transportado para, por exemplo, o direito do Estado de limitar condutas dos indivíduos (poder de polícia no Direito administrativo) ou, ainda, de o direito do Estado de fazer valer suas decisões judiciais de forma coercitiva (Direito Processual) etc.

Muito embora essa resposta dada com base nas teorias contratualistas sejam convincentes e sedutoras, uma reflexão um pouco mais detida do aluno após a aula lhe trará dúvidas irrespondíveis. Pode pensar o aluno: seria mesmo que as pessoas consentem em ceder parte de sua liberdade? E quanto de liberdade deve cada um ceder? Será que todos concordar em ceder porções diferentes? A pessoa sobre a qual recai a punição concorda com a

${ }^{26}$ FOUCAULT, Michel. Em defesa da sociedade. Trad.: Maria Ermantina Galvão. São Paulo: Martins Fontes, 2008. p. 16. acontecer. Ou serão respondidas se o aluno prolongar seus estudos até os mais elevados níveis nos cursos de pós-graduação.

Passemos agora a denunciar com alguns casos e exemplos o problema do ensino jurídico baseado na concepção do poder soberano. Algumas questões jurídicas atuais de alta complexidade social que estão na pauta de nossos tribunais ou situações de imensa aflição e dor sobre quem é exercido o poder; mas que não recebe a atenção devida pela sociedade e muito menos pelo Direito.

Primeiro, podemos citar o exercício de poder do carcereiro sobre o condenado penal. O exercício de poder do carcereiro sobre o condenado pode ser muito maior do que o juiz exerce. O poder do juiz sobre o condenado limita-se ao poder soberano, de condenar ou absolver, de exercer o poder punitivo estatal ou não. Por outro lado, o carcereiro exerce sobre o condenado o poder disciplinar que não tem controle do Estado, dilui-se no trato diário da prática penitenciária, mas que mostra-se muito mais aflitivo ao condenado do que a própria condenação, pois se fossem cumpridas as regras soberanas (no caso cumprimentos das regras da Lei de Execução Penal) o preso poderia aceitar a condenação como forma de expiação de seu mal causado.

Segundo, o poder exercido pelo policial militar que é quem exerce efetivamente a criminalização secundária. No contexto da filosofia do contrato social pensa-se que o exercício da criminalização primária pertence ao legislador que o exerce por meio da tipificação de fatos como crimes. Já a criminalização secundária (subsunção de um caso concreto aos tipos-crimes abstratos da norma) pertencente ao juiz. Ocorre que, essa noção - ideal, diga-se - não se efetiva no dia-a-dia da complexidade social, notadamente, diante de nossa realidade marginal latino-americana. Quem exerce a criminalização secundária é a polícia, uma vez que somente os fatos selecionados (ativa ou passivamente ${ }^{27}$ ) pela polícia é que serão levados para a justiça penal.

Ou seja, impossível explicar esse exercício de po-

\footnotetext{
${ }^{27} \mathrm{Ou}$ seja, ativamente: um fato que não configura crime é selecionado pela polícia como se crime fosse, levando os fato às instancias penais; passivamente: um fato que configura crime, a polícia não leva para o conhecimento do poder judiciário, pelos mais diversos fatores ou interesses que podemos elucubrar.
} 
der a partir de uma concepção do poder soberano; pois, o exercício do poder (do) soberano é aquele exercido no estrito cumprimento da lei (em razão da legalidade estrita direcionada aos atos da Administração pública) e lei, por sua vez, é aquela expedida pelo poder legislativo competente; logo, de acordo com esse raciocínio, os atos praticados fora do Direito não recebem regulamentação normativa. Assim, vê-se necessário que haja uma inversão do papel do juiz para deixar sua posição clássica de realizador da criminalização secundária para uma posição de contentor do poder arbitrário do Estado.

Terceiro, a regulamentação de drogas pela ANVISA (Agência Nacional de Vigilância Sanitária). Em última análise, quem pratica a criminalização primária dos crimes de tráfico de drogas é a ANVISA, ou seja, o poder executivo, sem a participação da representação democrática (indireta) do poder legislativo. A ANVISA por meio da Portaria 344/1998 é que preenche os tipos penais (em branco, assim chamados pela doutrina) da lei de drogas.

Veja-se quem pratica a seleção dos elementos tipificantes é o saber médico, ou seja, um conhecimento cuja criação não surgiu do poder soberano, mas sim do poder exclusivo de poucos; saber cujo acesso é restrito à determinadas pessoas detentoras da linguagem técnica.

Um parênteses antes de continuarmos: o que queremos demonstrar aqui é a impossibilidade de expor aos alunos de graduação que a origem desses manifestações seriam - em tese - do poder político monopolizado pelo Estado, quando a realidade manifesta-se de forma escancaradamente oposta e por diversos atores sociais, muitos deles sem nenhuma ligação com o Estado ou sequer podem ser identificados por este.

Continuando.

Quarto, se o site de buscas Google decidisse que as buscas de nome de determinada pessoa não terão nenhum resultado, por exemplo, uma pessoa que fosse um defensor do livre compartilhamento de arquivos e obras autorais na internet. Seria um enorme prejuízo para ela, essa pessoa teria o campo de exposição de seus argumentos reduzidos por ato de um ente privado, porém, com repercussões ilimitadas, já que não se pode saber quantas pessoas deixariam de ler o que esse ativista publicasse na internet.

Veja: as concepções do Direito partidas de uma concepção de poder do tipo soberano são extremamen- te limitadas para explicar a existência dessas situações. É uma limitação da liberdade individual por uma pessoa privada, que não recebeu a legitimidade para atuar em nome do bem comum.

Agora lançaremos dois pontos principais que devem ser adotados pelos projetos pedagógicos das faculdades de Direito para que o ensino praticado em sala de aula seja condizente com a realidade social atual:

Uma primeira característica a ser assumida no ensino jurídico é a aceitação de que o Direito, na realidade atual, deve ser compreendido como uma forma de contenção do poder (qualquer poder). Para que os micropoderes e o biopoder não fiquem de fora da apreciação do Estado. Essa é a visão de Michel Foucault:

O sistema do Direito e o campo judiciário são o veículo permanente de relações de dominação, de técnicas de sujeição polimorfas. O direito, é preciso examiná-lo, creio eu, não sob o aspecto de uma legitimidade a ser fixada, mas sob o aspecto de procedimentos de sujeição que ele põe em prática. ${ }^{28}$

Abraçando essa concepção, um dos maiores doutrinadores de nosso país, Celso Antonio Bandeira de Mello, diz:

Existe uma impressão, quando menos difusa, fluida, mas nem por isto menos efetiva, de que o Direito Administrativo é um Direito em favor do Poder, a fim de que ele possa vergar os administrados." (2007, p. 42). E conclui o renomado jurista: "Portanto, o Direito Administrativo não é um Direito criado para subjulgar interesses ou direitos dos cidadãos aos do Estado. É, pelo contrário, um Direito que surge exatamente para regular a conduta do Estado e mantê-la afivelada às disposições legais, dentro desse espírito protetor do cidadão contra descomedimentos dos detentores do exercício do Poder estatal. Ele é, por excelência, o Direito defensivo do cidadão $[. ..]{ }^{29}$

No mesmo sentido, Túlio Vianna, Professor Adjunto de Direito penal da Universidade Federal de Minas Gerais, em sua tese de doutoramento, concebeu o Direito como instrumento de limitação de poder. Túlio Vianna, classifica os mecanismos de controle por meio de moni-

\footnotetext{
${ }^{28}$ FOUCAULT, Michel. Em defesa da sociedade. Trad.: Maria Ermantina Galvão. São Paulo: Martins Fontes, 2008. p. 32.

${ }^{29}$ Idem, 2007, p. 46.
} 
toramento $^{30}$, reconhecimento ${ }^{31}$ e registros ${ }^{32}$ como exercício de biopoder, assim, seria o Direito uma forma de limitação desses poderes.

\section{Segundo Túlio Vianna:}

Toda a dogmática jurídica até os dias atuais foi construída com base no modelo consensualista que concebe o poder como contrato-opressão. Até então os teóricos procuraram evitar a todo custo construírem uma teoria jurídica a partir de uma visão conflitiva do poder e do Direito [...] Faz-se necessário, no entanto, que se assuma a parcialidade do poder como algo a ele inerente e se construa uma nova teoria do Direito com base em um modelo realista do poder que não se funde em hipóteses consensualistas de um contrato social original ou de consensos comunicativos ideais, mas numa concepção realista do poder que se assuma parcial. ${ }^{33}$

Zaffaroni, reconhecido penalista argentino, incorporando esse pensamento criou o que se chama de funcionalismo redutor, segundo o qual o Direito (o Direito penal em especial) deve ser um dique de contenção do poder punitivo praticado pelo próprio estado (Direito penal formal), por pessoas fora do Estado, por exemplo, organizações criminosas (Direito penal paralelo) e por agente do Estado mas em dissonância com fins democráticos deste (Direito penal subterrâneo). ${ }^{34}$

\footnotetext{
30 "A monitoração eletrônica é uma técnica que utiliza instrumentos eletrônicos para ampliar os sentidos humanos e focalizá-los sobre determinados ambientes, comunicações ou pessoas, com fins de controle e/ou registro de condutas." VIANNA, Túlio Lima. Transparência pública e opacidade privada: o direito como instrumento de limitação do poder na sociedade de controle. 2006. 206 f. Tese (Doutorado em Direito) - Faculdade de Direito, Universidade Federal do Paraná, Curitiba, 2006. p. 27.

31 "O reconhecimento é uma técnica de comparação cuja finalidade é a detecção de uma possível congruência entre uma monitoração atual e uma monitoração passada memorizada em um registro." VIANNA, Túlio Lima. Transparência Pública e Opacidade Privada: o direito como instrumento de limitação do poder na sociedade de controle. 2006. $206 \mathrm{f}$. Tese (Doutorado em Direito) - Faculdade de Direito, Universidade Federal do Paraná, Curitiba, 2006. p. 27.

${ }^{32}$ Registro é o resultado da monitoração ou do reconhecimento; é o que fixou gravado, enfim registrado.

${ }^{33}$ VIANNA, Túlio Lima. Transparência pública e opacidade privada: o direito como instrumento de limitação do poder na sociedade de controle. 2006. 206 f. Tese (Doutorado em Direito) - Faculdade de Direito, Universidade Federal do Paraná, Curitiba, 2006. p. 143.
}

O segundo ponto a ser assumido na feitura dos projetos pedagógicos das faculdades de Direito é a aceitação da existência de poderes para além do pode soberano.

Uma concepção presa à ideia de que todo poder é exercido pelo Estado (pelo soberano) é uma visão inocente que implica na redução drástica da complexidade das relações sociais, fazendo com que os alunos saiam da faculdade sem o suporte de conteúdo básico necessário para aplicar o Direito diante de um caso concreto.

Se o aluno traz consigo essa concepção idealizada da criação do Direito e da conformação da sociedade baseada no consenso e no contrato social, quando ele é exposto aos fatos reais - caracterizados por uma intensa conflituosidade onde estão em jogo interesses diversos e antagônicos - a capacidade de compreensão e busca de solução fica inviabilizada. Se o aluno é incapaz de entender o próprio fato, muito menos conseguirá aplicar o Direito.

Os fenômenos sociais são compostos por diversos fatores que implicam análises de diversos campos das ciências (economia, sociologia, psicologia, política etc.), abstraída a análise desses outros campos das ciências sociais resta a análise jurídica do fato.

Mas o que é importante deixar claro: não se trata de simplesmente incluir essas matérias na grade curricular, tal como acontece na maioria - senão em todas - as faculdades de Direito - trata-se, sim, de as matérias tradicionais do Direito (penal, civil, administrativo, constitucional etc.) serem analisadas a partir das diversas perspectivas soais, extraindo-se dos fenômenos o que é de relevância jurídica para uma solução - unicamente - jurídica.

\section{Conclusão}

Diante do que ficou exposto, cremos que é passada a hora de as grades curriculares e os projetos pedagógicos e, também, o próprio ensino jurídico em sala de aula, abandonem a concepção do Estado corporificado no Leviatã como fonte única de poder.

Para a compreensão de casos como: casamento entre pessoas do mesmo sexo, legalização da maconha, pesquisa com células tronco, legalização do aborto etc., necessitam uma compreensão da sociedade com múltiplas fontes de poder, sobretudo poder argumentativo ou retórico. 
Necessita-se ter a percepção de que grupos fora do Estado exercem poder sobre as decisões judiciais, e que não são grupos econômicos somente, mas grupos de diversos outros setores da sociedade que objetivam o ganho econômico, objetivam que a sua visão de mundo prevaleça sobre as demais, utilizando-se, para isso, o poder coercitivo do Estado.

Em suma, os projetos pedagógicos devem assumir a visão de o Direito ser hoje uma forma de contenção do poder e não uma forma de sua manifestação; e também assumir a riqueza da complexidade social nas diversas matérias do Direito.

Isso implica, na prática, a redução das disciplinas auxiliares do Direito nas grades curriculares e o aumento da carga horária das disciplinas jurídicas possibilitando uma abordagem dos temas com os seus diversos aspectos sociais, ressaltando o que for jurídico e excluído o que pertence às demais ciências sociais, de maneira a estabelecer a dialética construtiva entre essas ciências.

\section{Referências}

BECCARIA, Cesare Bonasena Marchesi di. Dos delitos e das penas. Tradução de Flório de Angelis. Bauru: Edipro, 2001.

FARIA, José Eduardo. Sociologia jurídica: direito e conjuntura. 2. ed. São Paulo: Saraiva, 2010.

FERREIRA FILHO, Manoel Gonçalves. O poder constituinte. 3. ed. São Paulo: Saraiva, 1999.

FOUCAULT, Michel. Vigiar e punir: história da violência nas prisões. 31. ed. Tradução de Raquel Ramalhete. Petrópolis: Vozes, 2006.
FOUCAULT, Michel. Em defesa da sociedade. Trad.: Maria Ermantina Galvão. São Paulo: Martins Fontes, 2008.

FOUCAULT, Michel. Segurança, território e população. São Paulo: Martins Fontes, 2005.

FRANÇA, Junia Lessa; VASCONCELLOS, Ana Cristina. Manual para normalização de publicações técnicocientíficas. 8. ed. Belo Horizonte: UFMG, 2007.

GONÇALVES, Sérgio Campos. O método arqueológico de análise discursiva: o percurso metodológico de Michel Foucault. História e-História, Campinas/SP: NEEUNICAMP, v. 1, p. 1-21, 4 fev. 2009.

GUSTIN, Miracy B. S.; DIAS, Maria Tereza Fonseca. (Re) pensando a pesquisa jurídica: teoria e prática. 2. ed. Belo Horizonte: Del Rey, 2006.

HOBBES, Thomas. Leviatã ou matéria, forma e poder de um estado eclesiástico e civil. Tradução de João Paulo Monteiro e Maria Beatriz Nizza da Silva. 2. ed. São Paulo: Martins Fontes, 2008.

MELLO, Celso Antonio Bandeira. Curso de direito administrativo. 22. ed. São Paulo: Malheiros, 2007.

VIANNA, Túlio Lima. Transparência pública $e$ opacidade privada: o Direito como instrumento de limitação do poder na sociedade de controle. 2006. 206 f. Tese (Doutorado em Direito) - Faculdade de Direito, Universidade Federal do Paraná, Curitiba, 2006.

ZAFFARONI, E. Raúl; ALAGIA, A.; SLOKAR, A. Derecho penal: parte general. 2. ed. Buenos Ayres: Ediar, 2002. 


\section{Para publicar na revista Universitas/JUS, acesse $o$ endereço eletrônico www.publicacoesacademicas.uniceub.br.}

Observe as normas de publicação, para facilitar e agilizar o trabalho de edição. 